\title{
Community owned solutions: identifying local best practices for social- ecological sustainability
}

\author{
Jayalaxshmi Mistry $^{1}$, Andrea Berardi ${ }^{2}$, Céline Tschirhart $^{1}$, Elisa Bignante $^{3}$, Lakeram Haynes $^{4}$, Ryan Benjamin $^{4}$, Grace Albert $^{4}$, \\ $\underline{\text { Rebecca Xavier }}^{4}$, Bernie Robertson $^{4}$, Odacy Davis $^{5}$, Deirdre Jafferally $^{5}$ and $\underline{\text { Géraud de Ville }}^{2}$
}

\begin{abstract}
Policies and actions that come from higher scale structures, such as international bodies and national governments, are not always compatible with the realities and perspectives of smaller scale units including indigenous communities. Yet, it is at this local social-ecological scale that mechanisms and solutions for dealing with unpredictability and change can be increasingly seen emerging from across the world. Although there is a large body of knowledge specifying the conditions necessary to promote local governance of natural resources, there is a parallel need to develop practical methods for operationalizing the evaluation of local social-ecological systems. In this paper, we report on a systemic, participatory, and visual approach for engaging local communities in an exploration of their own social-ecological system. Working with indigenous communities of the North Rupununi, Guyana, this involved using participatory video and photography within a system viability framework to enable local participants to analyze their own situation by defining indicators of successful strategies that were meaningful to them. Participatory multicriteria analysis was then used to arrive at a short list of best practice strategies. We present six best practices and show how they are intimately linked through the themes of indigenous knowledge, local governance and values, and partnerships and networks. We highlight how developing shared narratives of community owned solutions can help communities to plan governance and management of land and resource systems, while reinforcing sustainable practices by discussing and showcasing them within communities, and by engendering a sense of pride in local solutions.
\end{abstract}

Key Words: best practices; community owned solutions; environmental governance; Guiana Shield; Guyana; indigenous; participatory; system viability; visual

\section{INTRODUCTION}

Historically, governance strategies for natural resource management were dominated by centralized government institutions, transnational nongovernmental organizations, and industry (Cox et al. 2010, Ostrom and Cox 2010), where top-down solutions, usually under the control of professional experts, were deemed necessary to avoid local people overusing their resources (Dryzek 2005). However, since the 1980s, there has been growing recognition of accelerated and unrivalled ecological decline (e.g., Millennium Ecosystem Assessment 2005, Rockström et al. 2009), while at the same time, mounting evidence supporting the potential of local communities in playing a leading role in developing governance strategies for the sustainable management of natural resources (Ostrom 1999, Agrawal 2003, Berkes 2007, Blom et al. 2010, UNDP 2012). As many examples from across the world show, resource-based communities have the knowledge and practices essential for maintaining and promoting socialecological sustainability (Berkes 2012). Indeed, evidence from community-managed ecosystems across the tropics, such as indigenous territories, show that deforestation rates inside community-governed areas with strong legal recognition and government protection are significantly lower than in areas outside (Gaveau et al. 2009, Porter-Bolland et al. 2012, Carranza et al. 2014, Stevens et al. 2014).

Nevertheless, community-based natural resource management centered on customary governance arrangements is not a panacea (Berkes 2007, Ostrom et al. 2007), and not all local actions necessarily lead to sustainable management. Furthermore, in many cases, conservation outcomes may result not because of intentionality, but rather as a result of low demographics, limited market pressures, or unsophisticated technologies that limit the rate of exploitation. As communities become increasingly connected and embedded in national and international networks and systems, and the overarching social-ecological context changes, it is important to evaluate the efficacy of natural resource governance in local social-ecological systems to assess their robustness in current and future situations (Folke et al. 2005).

There is a large body of knowledge specifying the conditions necessary to promote the governance structures behind sustainable management of common pool resources (e.g., Ostrom 1990, 1999, Agrawal 2003) and effective (adaptive) comanagement (e.g., Armitage et al. 2009, Plummer 2009, Plummer et al. 2012). Although many of these conditions are context-specific, frameworks to capture some of the commonalities have been developed, most notably Ostrom's social-ecological system framework and design principles (Ostrom 2009, Cox et al. 2010, McGinnis and Ostrom 2014). These design principles, for example, have been used to evaluate and diagnose various local social-ecological systems, including community-managed forests and fisheries (e.g., Poteete and Ostrom 2004, Cox et al. 2010, Galappaththi and Berkes 2015).

Although a systems level analysis and understanding is essential for addressing the complexity of human-environment relationships, there is a parallel need to develop practical methods for operationalizing the evaluation of local social-ecological systems to help with planning governance and management of land and resource systems. Furthermore, taking a participatory approach for evaluating social-ecological systems that focuses on the views and perspectives of the resource users, is not only

${ }^{1}$ Royal Holloway University of London, UK, ${ }^{2}$ The Open University, UK, ${ }^{3}$ University of Torino, Italy, ${ }^{4}$ North Rupununi District Development Board, Guyana, ${ }^{5}$ Iwokrama International Centre, Guyana 
socially just (Pain et al. 2012), but has the potential to make natural resource management more democratic (Stringer et al. 2006). In this paper, we describe a systemic and participatory visual approach for engaging local communities in an exploration of their own social-ecological system. We use Hartmut Bossel's system viability framework (Bossel 2001) to support communities in assessing the state of current practices, and specifically, we ask the following: How do the indigenous communities view their social-ecological system as currently configured? What are the common threads linking practices identified by communities themselves as robust? What is the role of community-led assessment within an increasingly global environmental management and governance context?

\section{System viability and participatory visual methods}

The system viability framework (Mistry et al. 2010) is a simplification and adaptation of orientor theory developed by Hartmul Bossel $(1999,2001,2007)$ to assess the state or viability of different systems including communities, regions, nations, and policies. When we adapted Bossel's orientor theory in our investigations, we proposed that systems are social constructs determined by people's values and experiences, and that system viability enables distinct stakeholder groups, such as communities, to surface their values and agency by allowing them to express what they perceive to be the strategies required for their system of interest to survive in the long term (Berardi et al. 2015). These strategies are the following (Berardi et al. 2014):

1. Existence: the ability to get the resources for basic survival under normal environmental conditions that do not change over time or that go through a recurring pattern of predictable change, like the seasons of the year. To cope with the normal environmental condition, communities focus on key existence strategies, which may include creating shelter, provisioning basic food requirements, or responding to routine changes in the seasons;

2. Ideal performance: the ability to make the best use of limited resources in the environment. In these circumstances, communities develop strategies that can be characterized through ideal performance, i.e., developing highly efficient means of using scarce resources. These scarce resources can be anything from dwindling fish stocks, to expensive agricultural fertilizer, to limited time availability;

3. Flexibility: the ability to have a range of options or choices in a highly varying environment both over time and space. Here, communities develop flexibility strategies so that they can make the most of resources when they do appear, while having alternatives when certain resources disappear. Planting a range of crop species, or developing a range of livelihoods, are examples of how communities can cope with variety in the environment;

4. Resistance: the ability to cope with temporary variability in the environment that can sometimes be random and unpredictable, but rarely permanent. Examples include occasional floods or droughts. In these situations, communities develop resistance strategies - approaches to withstand these temporary changes. Accumulating certain resources, such as food reserves or savings in bank accounts, or falling back to traditional methods of survival, are examples of coping strategies for variability in the environment;

5. Adaptability: the ability to change practices to cope with major and permanent change in the environment. In this situation, the environment changes from what has been experienced in the past, to create a totally different environment, i.e., things do not change back to how they used to be, or they continue changing. When permanent change occurs, the best strategy a community can take is to adapt, i.e., develop new, innovative ways of dealing with the different conditions. Adopting new forms of communication or transportation are examples of coping strategies for major and permanent changes in the environment;

6. Coexistence: the ability to survive with other systems outside the system or, in the case of a community, the ability to survive with communities or organizations outside the community. Communities are constantly challenged by, or gain significant benefits from, outside organizations, whether these are neighboring communities, government institutions, or private/civil society organizations. In these situations, coexistence strategies make the most of the opportunities and protect the community against threats.

Tensions and trade-offs are inherent within the various system viability strategies. For example, a community's requirement to secure resources for basic survival can often conflict with its ability to share these resources with other communities. A community may decide to make best use of limiting resources, such as human capital, by investing in optimizing certain practices, which may conflict with its ability to maintain a wide range of practices so as to give maximum flexibility. In another case, a community may resist change by investing in existing traditional practices that could conflict with its ability to adapt to novelty within its environment by investing in new practices. However, system viability strategies are not always perceived to be mutually exclusive. For example, adaptations to incorporate novel information and communication technologies can sometimes help to preserve, reinvigorate, and reinforce traditional cultural practices that would have otherwise been lost as older generations pass away. Fundamentally, system viability moves away from a unidirectional normative judgement that suggests that one strategy for survival is clearly wrong and another is clearly right, e.g., from "undeveloped" to "developed" as implied in the term "sustainable development." Instead, it allows people to appreciate that every system has its tensions, and often the challenge is to find the appropriate balance between strategies, or preferably, survival strategies that act synergistically.

The principle behind using a participatory approach to the application of system viability was to allow local communities to analyze their own situation by defining indicators of successful system viability strategies that were meaningful to them, collecting indicator data, and analyzing the emerging data through learning by doing (Reed et al. 2005, 2008, Stringer et al. 2006, Fernandez-Gimenez et al. 2008). The aim of using a visual approach to communication within the participatory process was twofold. First, the methods of participatory photography (PP; Bignante 2010) and participatory video (PV; White 2003, Lunch 
and Lunch 2006, Milne et al. 2012) enable participants to identify systems of interest on their own terms using a communication mode that is familiar to them (visual compared to textual), while at the same time stimulate people's interest in, and engagement with, the research. Second, visual approaches take a marked departure from the linear logic of the written form, enhancing existing indigenous systemic and relational logic, thus allowing more information to be perceived simultaneously, with the positioning of information within the three-dimensional visual space becoming as important as the inclusion of distinct items of information (Mistry and Berardi 2012, Mistry et al. 2015a). The visual representation of information is therefore a more systemic approach to identifying and sharing indigenous indicators of system viability because the complex imagery often communicates the sophisticated message that "the whole [picture] is greater than the sum of its individual parts."

\section{Study context and approach}

We present findings from Project COBRA (http://www. projectcobra.org), a three-year research project funded by the European Commission 7th Framework program involving research, civil society organization (CSO), and business partners from Europe and South America working with indigenous communities across the Guiana Shield region of South America. The Guiana Shield covers an area of 2.5 million $\mathrm{km}^{2}$ extending from Colombia in the west to Brazil in the east, and as well as containing an estimated $10 \%-15 \%$ of the world's fresh water reserves, it is also part of the world's largest contiguous block of tropical forest (Hammond 2005). With its vast wealth of natural resources, the Guiana Shield is the focus of various extractive industries and large infrastructural projects, such as mining, logging, dams, and agricultural expansion, but has also been targeted by major conservation funding schemes, most notably under the climate change mitigation REDD+ scheme (Berardi et al. 2013a). Within this context, many indigenous peoples who still retain considerable knowledge and skills for sustainable governance of the region continue to be largely excluded from political, economic, social, and cultural life, and many communities still do not have any land rights over the traditional territories within which they make their livelihoods (Hall and Patrinos 2005). The overall aim of Project COBRA therefore was to "establish how community owned solutions for the management of natural resources have the potential to act as showcases for the world in determining the most effective and efficient use of emerging funding streams in order to maximise social justice and ecological sustainability."

In this paper, we present research undertaken within Project COBRA on supporting indigenous communities in assessing the state of current practices in the North Rupununi region of Guyana. The North Rupununi, located in the southern part of Guyana (Fig. 1), comprises savannas, wetlands, and forest ecosystems, which support a rich biodiversity of both terrestrial and aquatic life, and provide a wealth of natural resources for the indigenous Makushi and Wapishana communities that inhabit the area (Wetlands Partnership 2006, 2008, Mistry et al. 2004). A CSO, the North Rupununi District Development Board (NRDDB) represents the interests of the 6000-8000 people who live in the North Rupununi, whose main economic activities are subsistence fishing and farming, although some communities have taken the step to develop alternative livelihoods, such as ecotourism, shop keeping, poultry rearing, and producing traditional agricultural-based products at commercial scales. Through a series of consultations with the NRDDB and its 16 constituent villages, Apoteri, Rupertee, and Fairview were chosen for the research.

Fig. 1. Map showing the studied villages in the North Rupununi, Guyana, within the context of the Guiana Shield region.

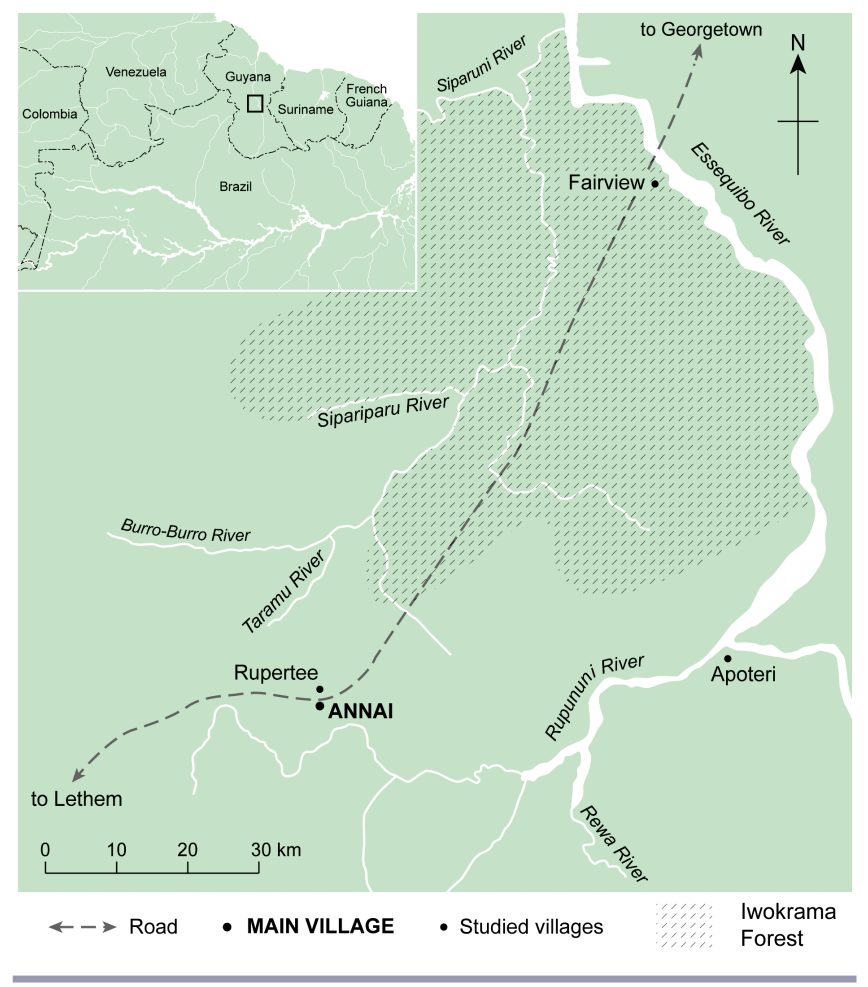

Apoteri is a remote forest community that can only be reached by a 30-min car ride followed by a 3-hour boat journey from the Brazil-Georgetown road. Subsistence farming and fishing are the main livelihood activities, although a few people were previously employed in a nearby conservation concession managed by the CSO Conservation International. Rupertee is a savanna community situated beside the Brazil-Georgetown road, but also in the Annai Village political and administrative unit, which is well connected through an airstrip, an ecotourism center, and a local training institute. Fairview is also close to the BrazilGeorgetown road, but situated away from the regional hub, and within a protected area, the Iwokrama Forest. Fairview has a strong relationship with Iwokrama, for example supplying a significant workforce to the organization's field center. Although these three communities share many social-ecological characteristics, they also have clear distinctions that provided an opportunity to explore whether there were any common system viability strategies.

Our approach to working with the communities focused on a flexible and participatory research design using a simple participatory action learning cycle (plan, act, observe, evaluate); we did not use these steps in a systematic way, but as a heuristic to encourage continuous and collective assessment and reflection 
on the research process and outcomes by participants and ourselves. In addition, our engagement with the local communities was through a team of five local indigenous researchers (also authors on this paper) who could play a bridging role in terms of access to participants, language issues, culturally appropriate conduct of research, and potentially provide continuity beyond the project period (Wheeler 2009, Kamuya et al. 2013). Working through the many challenges (and successes) of participatory work, reflected on in detail in Mistry et al. $(2015 b)$, the indigenous researchers facilitated all the activities at community level including initial consultations to gain free, prior and informed consent, implementation of research methods, and dissemination back to the communities and the NRDDB.

\section{METHODS}

The research process took place over two years in a staged but iterative process shown in Figure 2. The local indigenous researchers visited the villages to discuss, identify, film, and photograph community viability strategies through a series of community consultations engaging with a wide cross-section of people including women, men, and youth. The activities used to convey concepts such as system viability involved participatory exercises and games with community members detailed in Berardi et al. (2014). At the same time, viability strategies and associated data were captured using PV and PP, and then edited into films and photostories by the indigenous researchers. These films and photostories were screened back to the communities, thereby allowing people to provide feedback, comments, and reflection to modify the films and photostory representations. This normally went through at least three iterations so that a sense of consensus within the community could be reached. Both young people and elders, as well as males and females (with a slight majority of women attending with their children, the average numbers were $20-25$ people per meeting), participated in these meetings. The video and photographic materials (1 film and 58 individual and collective photostories were produced in each community) were then submitted to the project academic researchers, and were analyzed through an iterative process of coding individual segments/photos based on visual and audio content into themes using the NVivo qualitative software. The results were then presented to the indigenous researchers in the form of spray diagrams; these show the connections between related elements and can be thought of as a conceptual map of a situation or issue (Open University 2002). Through in-depth discussions, the representations of viability strategies and their relationships were validated and refined where necessary, and then presented back to the three villages in the form of revised spray diagrams for final agreement and comments. A detailed analysis of the visual representations in the PP and PV are provided in Mistry et al. (2015a).

The viability strategies were then allocated indicators (How does the community measure the state of this important element of their viability?) and thresholds (What is the community's level of tolerance before it considers this element in a bad state?). This was done using a qualitative scoring system of $1-3$, where $1=$ inadequate, 2 = acceptable, and $3=$ good, following other indicator studies including Mistry et al. (2010), Béné et al. (2011), and Davis et al. (2013). The data for this activity was triangulated from information captured in the films and photostories, experience and knowledge of the indigenous researchers, and meetings organized in the communities to discuss and agree indicator status and thresholds. This allowed us to see which strategies communities themselves thought were working well and those that were not.

Fig. 2. Main steps leading to the selection of six best practices in the North Rupununi, Guyana.

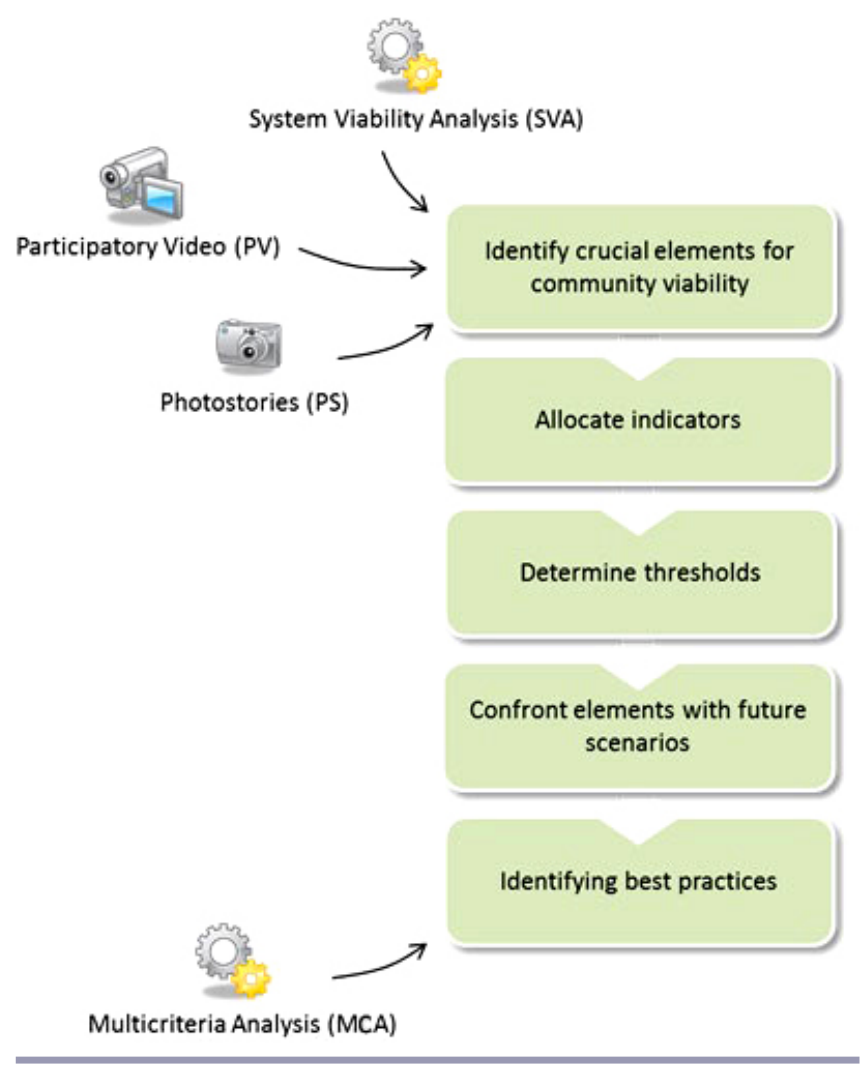

However, to be able to assess the state of current practices in detail and investigate what made them robust, within practical considerations of time and logistics, we needed to identify a subset of practices. In addition, the next phase of Project COBRA involved sharing best practice strategies with other communities around the Guiana Shield (Tschirhart et al. 2014, 2016), as well as stakeholders at higher levels of decision making, so we needed to be able to clearly communicate the best practices through PV and PP. Therefore, a Multicriteria Analysis (MCA) was conducted on the whole set of system viability strategies identified by the communities. This method was chosen because it provided a structured approach for comparing different options, i.e., the viable strategies, and for selecting the most suitable ones according to overall preferences, i.e., the criteria (Belton and Stewart 2002). The options can be compared by being rated against a set of criteria that represent different desirable objectives (Mendoza and Prabhu 2005, Khadka and Vacik 2012). The options that manage to fulfil the highest number of desirable objectives are thus very likely to be selected (Recchia et al. 2011). The criteria for the MCA were developed through a discussion with the indigenous researchers and the communities, based on, for example, status of the strategy, its relevance to the wider North Rupununi communities, and whether it could be effectively communicated through film and photostories. 
One of the criteria agreed upon was whether a current community strategy would be fit for the future. This was important because in their films and photostories all the communities emphasized the importance of maintaining their environment and culture for future generations (Mistry et al. 2015a). A participatory exploration of future scenarios was carried out with the communities over a six-month period; there is no scope to describe the process in detail here, but a full critical evaluation of the process and outcomes is provided in Mistry et al. (2014). Another important criterion was whether the strategy fulfilled the project's definition of a "community owned solution," adapted from the UNDP (2012): practices that are born, developed, and successfully implemented in the community, by the community, without major influence from external stakeholders, and that contribute to social-ecological well-being in a fair and equitable way (Berardi et al. 2014). We also agreed with the communities that it was important to find people who were role models for different strategies, that is, people who felt passionate about the strategy and had the knowledge and skills to demonstrate how the strategy worked. Having these "champions" was therefore also included in the criteria list.

Each criteria of the MCA was allocated a weight (from $0=$ no importance at all, to 1 = very high importance), to reflect the multiple objectives of the project. Indeed, it was agreed by the project team and the communities that criteria representing community perspectives and practicality, such as whether it fulfilled the elements of a community owned solution, the level of transferability of the strategy, and the presence of champions who could represent and execute the strategy well, would be given priority. A final score for each strategy was calculated by multiplying the rates by their weights for each element, and then summing them up. The MCA allowed the identification of a subset of strategies, termed "best practices," for further investigation. Undertaking an in-depth study of these best practices was important to understand critical underlying factors for their success, and using PV and PP allowed a shared understanding of the practices to emerge. During discussions with the indigenous researchers about the MCA results, it became apparent that a study of all the identified best practices would not be possible in the timeframe of the project. Therefore, a collective decision to focus on one practice per system viability category was made based on discussions about time, budget, and logistical constraints (e.g., geographical accessibility, transport links), and the sensitivity of the information collected (e.g., researching traditional medicine would require another community consultation process on intellectual property rights beyond the scope of the project).

The indigenous researchers then started a six month PV/PP study of these six best practices, facilitating an informal and fluid process in the communities and with identified champions. The work involved discussing, capturing, and editing material, screening draft films and photostories, and then using feedback to finalize the visual products (these can be viewed at the Project COBRA web site). The video and photographic materials on the best practices were submitted to the project academic researchers, and were analyzed through an iterative process of coding individual segments/photos based on visual and audio content into themes using NVivo. These themes were verified through informal interviews with the indigenous researchers and through research diary entries of the project academic researchers who visited the region during this phase of the project.

\section{RESULTS}

\section{Participatory assessment using system viability}

The three communities identified over a hundred different socialecological elements that they perceived contributed to their viability strategies. These included natural resources (e.g., trees, rivers, medicinal plants), objects (e.g., solar panels, generators, radios), issues (e.g., keeping youth in the village), institutions (e.g., village councils, CSOs, local and national government), and livelihood activities (e.g., farming, hunting, fishing). An example of a spray diagram depicting a complete system viability analysis developed for the village of Rupertee is shown in Figure 3. As can be seen, indicators were often organized in nested hierarchies, with higher level categories, such as "the presence of forests" incorporating lower level indicators such as the availability of a particular medicinal plant. In addition, the indicators resulting from our participatory visual approach were highly qualitative, contextual, and covered a wide range of issues. For example, "timber" was identified as a crucial element for the viability of all three communities. The status of timber resources was directly linked to the way the communities managed the timber resources. As a consequence, the proposed measurable indicator of "timber" was "people knowing how (equipment), what (species), why (purposes), when (growth) and how much to extract." The threshold was when the "majority of people have traditional knowledge and modern equipment to extract timber." So, to maintain a healthy environment in order to sustain the regular and predictable production of the basic resources for survival, and to maintain traditionally sustainable resource extraction practices in the community, the communities make sure they not only practice timber extraction according to intimate traditional ecological knowledge, but also make sure this knowledge is passed on to younger generations through participation in forest-based activities. This not only reflects the highly context-specific nature of how people perceive and experience their environment, but also shows that even though the communities are heavily reliant on natural resources, their indicators rarely relate directly to just the state of the resource (e.g., extent of forest, numbers of trees).

The identification of strategies under each system viability category between the three communities is analysed and discussed in Berardi et al. (2013b) and Mistry et al. (2015a). We found that there were similarities between the communities in terms of existence strategies (all three communities felt that access to land and waterways was a fundamental prerequisite for their continued existence), ideal performance (all three communities had practices that promoted the efficient use of titled land), flexibility strategies (all three communities aspired to the development of more options for food and health security), resistance strategies (all three communities had practices that kept traditions alive and protected the environment), adaptability strategies (all three communities used nonindigenous technologies in ways that significantly improved their well-being), and coexistence strategies (all three communities sought effective partnerships at regional, national, and international levels).

At the same time, each community showed specificities in regard to its unique social-ecological context. In Apoteri (see http:// 
Fig. 3. Example of an indicator spray diagram.

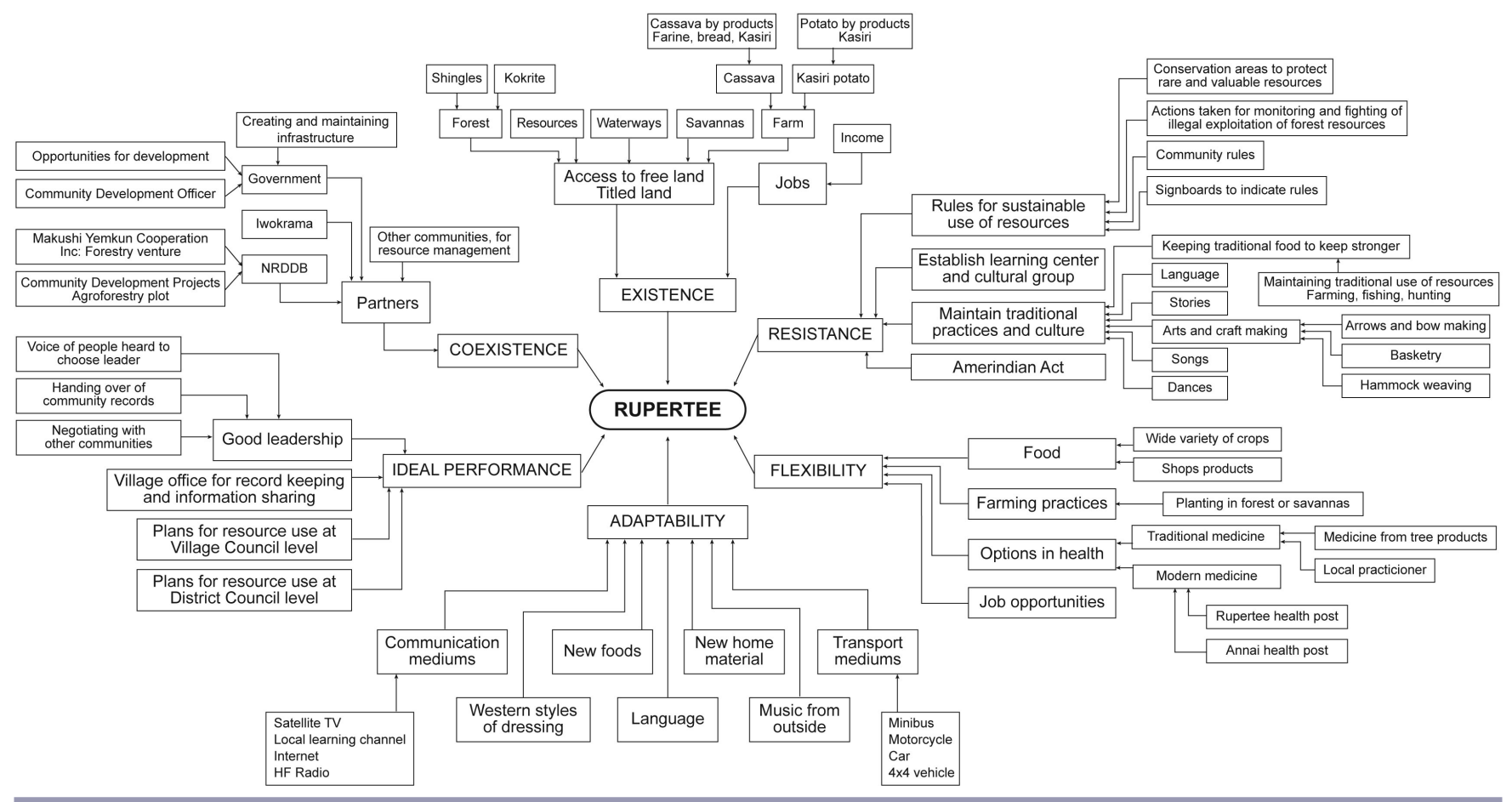

projectcobra.org/community/apotericommunity), their existence and flexibility strategies were characterized by a strong focus on traditional and innovative farming techniques, while their resistance and ideal performance strategies focused on solutions to maintain a healthy age structure and prevent youth from migrating. Apoteri also recognized self-help as a key component of their ideal performance strategy. These specific strategies reflected a community weakly connected to the outside world, relying more on its own internal strengths and resources, and facing the challenge of keeping younger generations in the village. The Fairview viability strategies (see http://projectcobra.org/ community/fairview), on the other hand, were oriented toward following the rule of law and management plans for their village, partly to comply with the rules that regulate the surrounding protected forest while making the most of their particular situation. For example, their existence strategy emphasized access to education, their resistance and ideal performance strategies focused on enforcing the rule of law and community management plans for sustainable resource use, the flexibility strategy highlighted the creation of job opportunities, while their coexistence strategy pointed out their working partnership with Iwokrama. Rupertee is situated in a context that highly exposes it to the outside world, and this is reflected in many of their viability indicators that were aimed at engagement with, and protection from, external impacts (see http://projectcobra.org/ community/rupertee), emphasizing the creation of employment opportunities as one of their main existence strategies, while their resistance strategy focused on their programs to preserve traditional culture. The use of communication technologies were highlighted as one of their most important adaptability strategies, while district level planning and partnerships with other communities and organizations were identified as key ideal performance and coexistence strategies, respectively.

\section{Identification of best practices}

A summary of the MCA analysis is shown in Table 1, with the short listed best practices agreed with the communities to be investigated in more detail shown with an asterisk. These were traditional fishing (existence), transmission of culture to youth (resistance), traditional farming practices (flexibility), community radio (adaptability), self-help (ideal performance), and successful partnerships through a local CSO (coexistence). Table 2 outlines the key aspects of each best practice, and the challenges it attempts to address, identified through the analysis of each best practice film and photostory, and verified through work with the communities and champions, and field notes. Note that these essential characteristics for the emergence of a successful survival strategy may not have been directly articulated verbally by community members. However, in many cases, these components were repeatedly manifested visually within the videos and photostories (for example, clips of different aged people doing tasks together showing knowledge transfer, as well as community cohesion), thus allowing us to identify these as significant. Crucially, this is a fundamental advantage over the written word, in that one is able to identify tangible significance within the media that would otherwise not have been detectable with written forms of communication.

Our analysis of these best practice videos and photostories, combined with triangulation through community interviews and research diaries, found that there were some cross-cutting themes that united the particular cultural, historical, and environmental context of each best practice. All were imbued with indigenous 
Table 1. Summary of the Multicriteria Analysis (MCA) analysis, with the short-listed best practices agreed with the communities to be investigated in more detail shown with a dagger $(\dagger)$. Column headings and weightings: $\mathrm{A}=$ Does the strategy have a satisfactory status? (1); $\mathrm{B}=$ Was the indicator well thought through? (0.6); $\mathrm{C}=$ How many other communities are using this strategy? $(0.5)$; $\mathrm{D}=$ Does the strategy contribute to make the best case scenarios happen? (1); E = Is the strategy community owned? (1); F = Is the strategy easy to capture through video and photos? (1); $\mathrm{G}=$ Are there people who can represent and execute the strategy well? (1); H = How transferable is the strategy? (1).

\begin{tabular}{|c|c|c|c|c|c|c|c|c|c|}
\hline $\begin{array}{l}\text { Orientor } \\
\text { Strategy }\end{array}$ & A & $\mathrm{B}$ & $\mathrm{C}$ & $\mathrm{D}$ & $\mathrm{E}$ & $\mathrm{F}$ & $\mathrm{G}$ & $\mathrm{H}$ & $\begin{array}{l}\text { Total } \\
\text { score }\end{array}$ \\
\hline \multicolumn{10}{|l|}{ Existence } \\
\hline Traditional and modern timber extraction & 1 & 1 & 1 & 0.6 & 1 & 1 & 0.8 & 1 & 0.93 \\
\hline Traditional fishing ${ }^{\dagger}$ & 1 & 1 & 0.6 & 0.6 & 1 & 1 & 0.8 & 1 & 0.88 \\
\hline Secure access to land rights & 0.8 & 1 & 0.6 & 0.6 & 0.8 & 0.5 & 1 & 0.6 & 0.74 \\
\hline \multicolumn{10}{|l|}{ Resistance } \\
\hline Practices for transmitting traditional culture to youth ${ }^{\dagger}$ & 1 & 1 & 1 & 0.5 & 1 & 1 & 1 & 1 & 0.94 \\
\hline Community rules for the use of natural resources & 0.5 & 0.8 & 0.6 & 0.7 & 0.5 & 0.7 & 0.6 & 0.5 & 0.60 \\
\hline Activities to encourage youth to stay in the village & 0.7 & 0.8 & 0.3 & 0.7 & 1 & 0.6 & 1 & 1 & 0.77 \\
\hline \multicolumn{10}{|l|}{ Flexibility } \\
\hline Maintaining a local health practitioner in the community & 1 & 1 & 0.6 & 0.5 & 1 & 1 & 1 & 0.7 & 0.85 \\
\hline Maintaining a variety of farming techniques ${ }^{\dagger}$ & 0.8 & 1 & 1 & 0.4 & 1 & 1 & 1 & 0.8 & 0.87 \\
\hline \multicolumn{10}{|l|}{ Adaptability } \\
\hline $\begin{array}{l}\text { Community and/or individual systems to adapt new mediums } \\
\text { of transport (e.g., renting system of boats and engines, so that } \\
\text { it benefits the whole community but is maintained in a good } \\
\text { state also) }\end{array}$ & 1 & 1 & 1 & 0.9 & 1 & 0.7 & 0.8 & 0.6 & 0.89 \\
\hline $\begin{array}{l}\text { Modern communication tools adapted for optimal community } \\
\text { and/or individual use and benefit e.g., community radio }{ }^{\dagger}\end{array}$ & 1 & 1 & 1 & 1 & 0.7 & 0.8 & 0.8 & 0.8 & 0.89 \\
\hline \multicolumn{10}{|l|}{ Ideal Performance } \\
\hline Self-help at household and community levels ${ }^{\dagger}$ & 1 & 1 & 0.3 & 0.7 & 0 & 1 & 1 & 1 & 0.87 \\
\hline $\begin{array}{l}\text { Effective planning and applications of community natural } \\
\text { resource plans }\end{array}$ & 1 & 1 & 1 & 1 & 0.9 & 0.5 & 0.6 & 0.7 & 0.84 \\
\hline Leadership (transparency, democracy, communication) & 1 & 1 & 1 & 0.9 & 1 & 0.6 & 1 & 0.6 & 0.88 \\
\hline \multicolumn{10}{|l|}{ Coexistence } \\
\hline Partnerships between communities & 0.8 & 1 & 0.3 & 0.9 & 0.9 & 0.8 & 1 & 0.5 & 0.76 \\
\hline Partnerships with NGOs ${ }^{\dagger}$ & 0.8 & 0.8 & 1 & 0.8 & 0.5 & 0.8 & 1 & 0.6 & 0.79 \\
\hline
\end{tabular}

knowledge. In some cases, indigenous knowledge played a direct role in establishing long-term communal understanding of people's environment and the transmission of pertinent experience through fishing (existence) and farming (flexibility), or participation in traditional dances and ceremonies (resistance). However, we also saw that indigenous knowledge is not static and is responding to social-ecological changes. For example, in the adaptability best practice of the community radio, Radio Paiwomak, a new form of communication was adopted by the communities that on the surface could potentially undermine indigenous knowledge and its transmission by facilitating the widespread communication of nonindigenous ideas and practices. Indeed, the national government at the time of this research insisted on the radio transmitting political messages from the state-controlled national radio station. Nevertheless, since its inception, the radio station has had many programs in the traditional language, and the fact that the radio was identified as community owned by the communities themselves, reflects its role in enabling the communities to use the radio to reinforce indigenous knowledge and stimulate traditional oral modes of communication (Fig. 4). There are, for example, traditional storytelling programs for children, radio programs broadcast in the indigenous language of Makushi, and programs facilitating the exchange of traditional knowledge to face new challenges
Fig. 4. An extract of the adaptability best practice photostory showing the different radio programs aired on the community radio station.

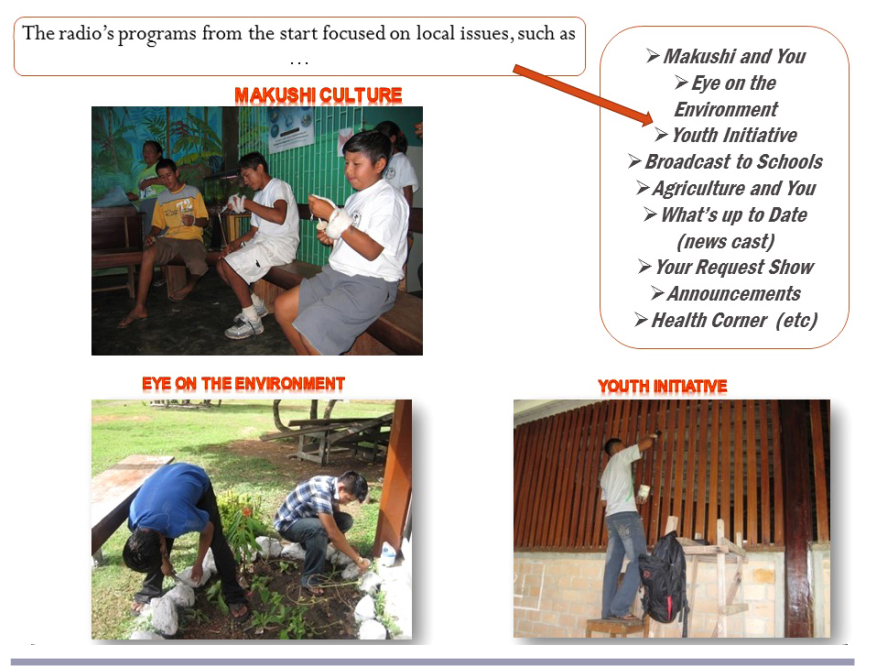


Table 2. Short description of each best practice studied and associated challenges.

Best practice

Key aspects of the best practice participatory video (PV) and participatory photography (PP) stories

Traditional fishing practices (Existence)

Know the different fishes' habitats, behavior, and optimal season or time of the day to target appropriately and be time efficient; Use a variety of fishing techniques and equipment according to the fish species targeted: bow and arrow for surface water fish, rod for midlevel fish, line and hook for deep or shallow water; Fishing with gill nets and seine is presented as a bad practice because the fishing process is not selective; Know how to build or where to get traditional fishing equipment (e.g., bow and arrow) and how to use it; Appreciate the quantity of fish needed and for what purpose; Make children/ family/friends observe and, even better, participate in fishing trips and in the preparation and cooking of fish meals to raise awareness from a very young age about the close link between natural resources and human survival.

Transmission of culture to youth (Resistance)

At community level: Invest your own time to inspire and lead cultural projects and activities if you are passionate and proud about your culture and knowledge; Encourage the elderly to share traditional knowledge with everyone, especially young people; Be inclusive of nontraditional forms of knowledge and communication, such as the radio and Internet, as a way of keeping young people interested and stimulated; Show and explain the purpose of carrying out certain traditional tasks, e.g., making useful everyday objects like baskets, and/or earning an income by selling them; Organize events and performances that bring the community together, old and young, to tell stories and perform traditional culture; Be aware of the diversity of cultures in the community, be inclusive; Record traditions and culture, for example, through visual methods, to save it for future generation and disseminate it as widely as possible; Create platforms for exchange and passing on of knowledge, through a culture group or campfire nights, performances, etc.

At family level: Speak in the traditional language to young children; Make young children participate in traditional tasks from a very young age; Take time for one-to-one sessions with children at home to pass on some knowledge through storytelling, for example.

Traditional farming practices (Flexibility) Have good knowledge of the environment so that opening a farm does not negatively affect an ecosystem on which the communities are dependant; Choose a good place to start a farm in light of quality of the soil and local topography; Select good cassava sticks and good crops, adapted to the different types of soils; Share knowledge by communicating and exchanging good practices, by making children and members of the community help an participate in family farming tasks; Have two farms, of different sizes, that are kept for different purposes and that reduce vulnerability to diseases, destruction by animals, floods, etc.; Have a range of diverse crops (cassava and noncassava); Know how to care for these crops; Know the potential products that can be made out of the different crops; Know how to prepare the different by-products; Make the most of farm products through family consumption and selling excess.

Community radio (Adaptability)

Consult the community to see if members are willing to have a radio, for what purposes, and where it would be based; Ensure that community members can interact with the community radio, for example, through HF radios, telephones, or even Internet; Ensure that the majority of the communities have the infrastructure to listen to, or are in range of, the radio; Identify at least one motivated person from the community to champion and run the radio, even as a volunteer to begin with if necessary; Choose a name to which community can relate to make it their own; Develop programs with the community's participation; Identify an institution or a group of people responsible for monitoring the radio's status; If initial support is needed (for training, for initial equipment, or some external expertise), identify optimal partnerships to help launch the project; Make sure it follows the national legislations, such as license of operation; Make sure the ambitions fit the infrastructure, such as power supply; Think of ways to sustain it at the local level, without too much external input in the long term; Make sure all members of communities, young, old, women, and men are represented in the programs.
Challenges this best practice addresses

To maintain a healthy environment to sustain the regular and predictable production of the basic resources for survival: food, water, shelter, medicine. With an increasingly unpredictable climate, and higher threats from extractive activities by local to international players, key resources are put under pressure jeopardizing the existence of the North Rupununi communities. Another challenge is to maintain, from one generation to the next, sustainable resource management. This is difficult because young people are leaving communities to pursue education or job opportunities, or simply as external equipment and/or external demand start being prioritized as a way of saving time or generating an income for engaging with consumer society, rather than maintaining ecologically sustainable self-sufficiency.

Within an increasingly globalized world, and within societies in which indigenous groups have for a long time been suppressed and marginalized, it can become increasingly challenging for indigenous communities to keep their cultural identity alive; "because of the absence of old people, because of exposure to other culture and traveling, because of lack of respect and interest in traditional skills, because of a decrease in sharing knowledge in the community and not only in the family, because of fear of the power of people with illegal traditional knowledge [it being misappropriated]" (Indigenous researcher). This presents two main challenges: first, it can affect community identity and togetherness, therefore weakening them as a community in the face of a variable environment; and second, it can affect the sustainability of their local social-ecological system.

Food security within a highly diverse environment; climate, diseases and pests, income, food supply, and job opportunities can vary significantly from one month to the next, or one year to the next. This variety can significantly challenge the food security of North Rupununi communities. Moreover, an income to enable communities to buy food when farm products are not sufficient is not always guaranteed, depending on job opportunities in the area.

Access to new media is constantly increasing in indigenous communities around the world: HF radios, mobile phones, television, computers, and Internet are becoming increasingly part of everyday lives. New communication tools both create the challenge (introducing new ideas and changing people's expectations) and have the potential to provide the solution (by keeping people informed on how to deal with change). Access to national and international news could override valuing local news, could increase the gap between younger and older generations, could threaten local lifestyles by presenting "better" lifestyles, and could even create inequalities in communities if access to media is not guaranteed for everyone. On the other hand, new media enables communities to understand the other systems with which they coexist, to have a wider understanding beyond the local, and communicate between themselves and to external organizations at the same speed as the speed of communication in other areas. New media can therefore be a powerful tool in light of changes in environmental governance happening at higher scales, as well as external activities such as mining, logging, and illegal fishing taking place in indigenous lands. The challenge is thus to keep the balance between valuing and serving the local, while understanding and being aware of the nonlocal. 
Self-help (Ideal Performance)

Have a leader: this is key. The leader must organize a self-help event very well so that community members participate and projects get carried out successfully. This involves getting the community together to organize the event in a participatory way: 1 . What task? This first step actually ensures that the community supports the project and willingly participates; 2 . When should it be carried out? 3. How long should it take? 4 . Who should participate? 5 . Who should do what according to capacity and skills? 6 . What resources are needed (how many people, what equipment ...)? 7. Is there a need for extra funding or equipment and if yes where to find it? Ensure the leader participates in the event to motivate community members and set the example; Organize food and drinks for participants ("nobody can work with an empty belly"); Who will prepare food and drink, what will be prepared and for how many people? Encourage men, women and youth to all participate because this brings the whole community together; Participation (financial or in kind) is compulsory for all villagers; Give warnings and fines for people who don't participate; If people cannot participate, collect their contribution before the event.

Successful partnerships through a local civil society organization (CSO; Coexistence) In consultation with community leaders, select communities that are willing, have some capacity, and have resources to actively participate; Build on existing community strengths; Hold meetings in the communities to explain the objectives, and organize activities in a participatory way, allocating different tasks and responsibilities to members of the community; Follow up the project at least every 3 months; organise meetings with all participants to evaluate activities, respond to concerns and queries, and provide additional support if necessary; Regularly communicate progress of activities to the wider community; Develop community owned rules with the help of experts/ facilitators if necessary; Provide adequate training using local expertise; Ensure continuity by providing support for training if needed and justified Support leadership to motivate community members to apply rules, follow guidelines, and actively participate; Implement self-help to carry out initiatives when funding or time is running out; Have determination and continuity; Network for visibility by establishing contact with reputable stakeholders; Monitor progress and impact of the project; Have transparency in accountancy whereby a percentage of the benefits go to the village council and the rest is returned to operations and improving infrastructure; Comply with national rules.
In remote areas of the world, public (and private) services are limited and cannot be relied upon to carry out day-to-day community activities, such as cleaning and maintaining communal spaces, or carrying out heavy tasks like cutting down patches of forest to grow a farm. Therefore, to maintain a clean environment in the community, recreation facilities like a football pitch, local infrastructure such as roads and bridges, and to provide for family necessities such as food, communities use self-help to get tasks done. And critically, selfhelp, at the same time, maintains a sense of togetherness and community spirit.

More and more development and environmental projects are being carried out in communities, with the support of external stakeholders. However, their success and sustainability is far from guaranteed. Infrastructure is being built, resource management projects are being developed, new forms of environmental governance are being initiated, commercial projects are being implemented, but all too often these projects do not succeed. This not only affects the local communities, but also the funding and supporting institutions that do not always get the expected return in terms of capacity building and impact. A crucial determinant for the successful implementation of a project for all parties involved, is the presence and effective functioning of a local $\mathrm{CSO}$ (such as fighting diseases within traditional rotational farming systems that avoid the use of artificial pesticides). At the same time, Radio Paiwomak has the potential to support communities in dealing with new, emerging challenges, such as the spread of HIV, a disease historically never experienced by indigenous communities. We also saw images in the photostory and film of people coming together to listen to the radio (Fig. 5), supporting communal interaction for indigenous knowledge production. In the coexistence best practice, the ecotourism enterprise was sustained by pooling traditional ecological knowledge for developing community owned rules for managing local fish resources and supporting local guides to appropriately guide tourists and ensure successful fishing trips.

The best practices identified also demonstrate the critical importance of prominent local leaders. The presence of at least one singular individual, highly motivated, respected as a local leader, with appropriate/innovative skills, and making a personal commitment and self-sacrifice to the best practice and the process of implementation was essential. The best practice champions varied between young and old, women and men (Fig. 6). However, they were all distinguished by community legitimacy - they were guided by collective benefits rather than self-interests -which gave the community confidence in their ability to make a difference and motivated community members to participate in the best practice. For example, the adaptability best practice of
Fig. 5. Uses of the community radio station depicted in the adaptability best practice photostory.

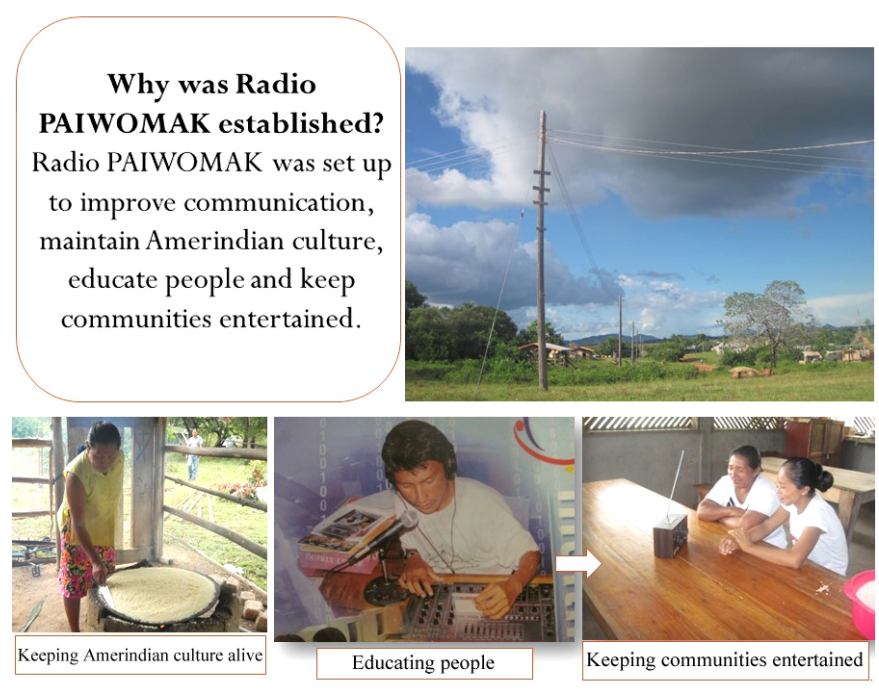

Radio Paiwomak relies on the radio manager's time and experience, and he is not always paid for his work. Not many people would 
work for the radio without getting paid, and in today's context of financial cuts, it is becoming even more difficult to compensate the radio manager's expenses such as transportation to and from the radio's headquarters. On the other hand, Radio Paiwomak has been operational for 13 years in this extremely challenging financial environment; clearly, there are mechanisms through which the radio continues to be operational even if this involves great sacrifices from one or more individuals.

Fig. 6. Champions of the resistance best practice.

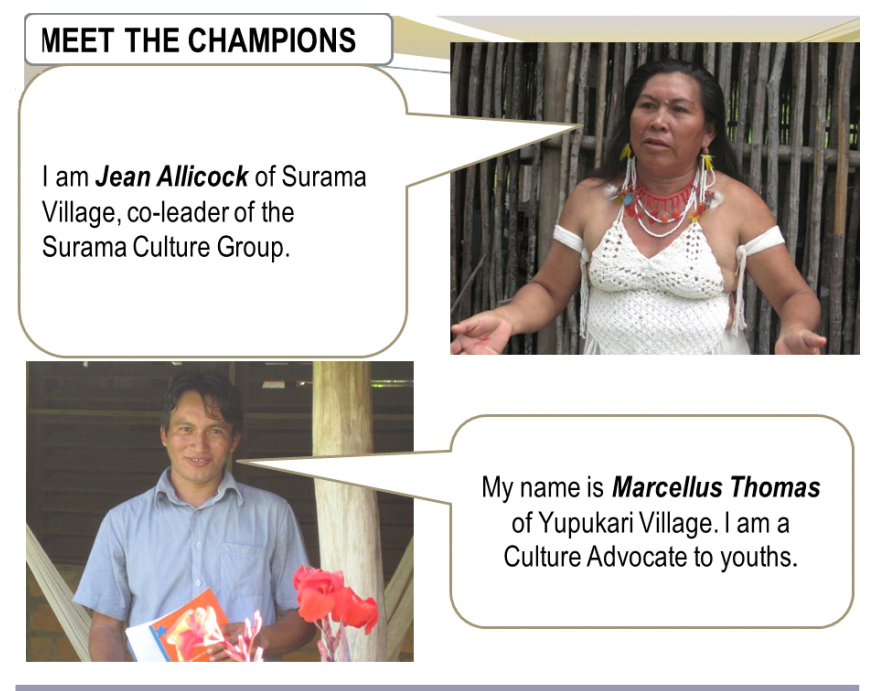

Linked to strong leadership was a sense of collectiveness underpinning many of the best practices. The ideal performance best practice of self-help embodies notions of community cohesion where norms, trust, communication, and connectedness in groups is the foundation of the best practice (Fig. 7). However, we also saw the importance of community cohesion within the coexistence best practice, where communities voluntarily work together to build infrastructure for the ecotourism venture, in the resistance best practice where people came together to teach young people about culture, and in the flexibility best practice where adequate food security through farming can only be achieved through a collective effort.

Most of the best practices are built upon an array of partnerships and networks. Crucial to their success is the role of the local CSO, the North Rupununi District Development Board (NRDDB), in helping to develop and support local community initiatives (Fig. $8)$. At the same time, links with external agencies and institutions have helped the local communities and the NRDDB to access necessary technical and business skills, new sources of finance, broaden market opportunities, and to gain political support, while at the same time retaining local control over the development agenda. The coexistence best practice is based on building partnerships to effectively develop and run communitybased enterprises. In the adaptability best practice, the roles of Iwokrama (national level CSO), UNESCO, the International Development Research Centre (Canada), and Guyana Broadcasting Corporation/National Communication Network are highlighted in the creation and maintenance of Radio Paiwomak. This indicates how successful initiatives often participate in many different partnerships at once, thereby taking advantage of different partner strengths and preventing overreliance on any single partner. It also shows, in the cases of Iwokrama and the National Communication Network, that longterm and ongoing support structures, which are not always exclusively financial, are required to strengthen and promote community owned approaches.

Fig. 7. Explanation of self-help in the ideal performance best practice photostory. Note that a "benab" is a conical palm thatched building normally used for meetings and social events.

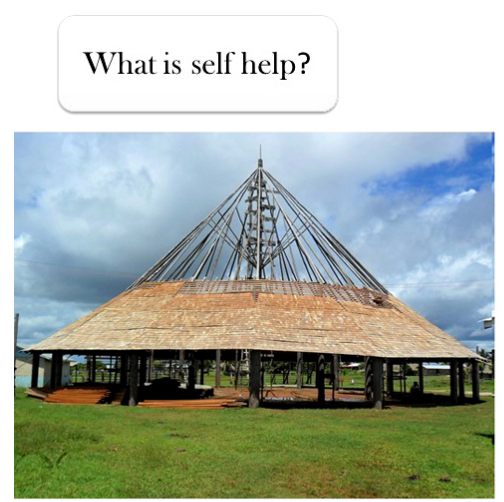

Construction of Annai benab through self help.
Self help is practiced in the

North Rupununi as a method of development through planning and organising by the village

leaders. The village leaders then mobilize people to participate in such community self help to maintain a healthy environment, infrastructure, development and community togetherness. Self help is a way

where communities can develop socially, culturally and economically.

It is said to be sustainable because it does not depend on funding unless there is heavy machinery required.
Fig. 8. The role of the North Rupununi District Development Board (NRDDB) in the coexistence best practice photostory.

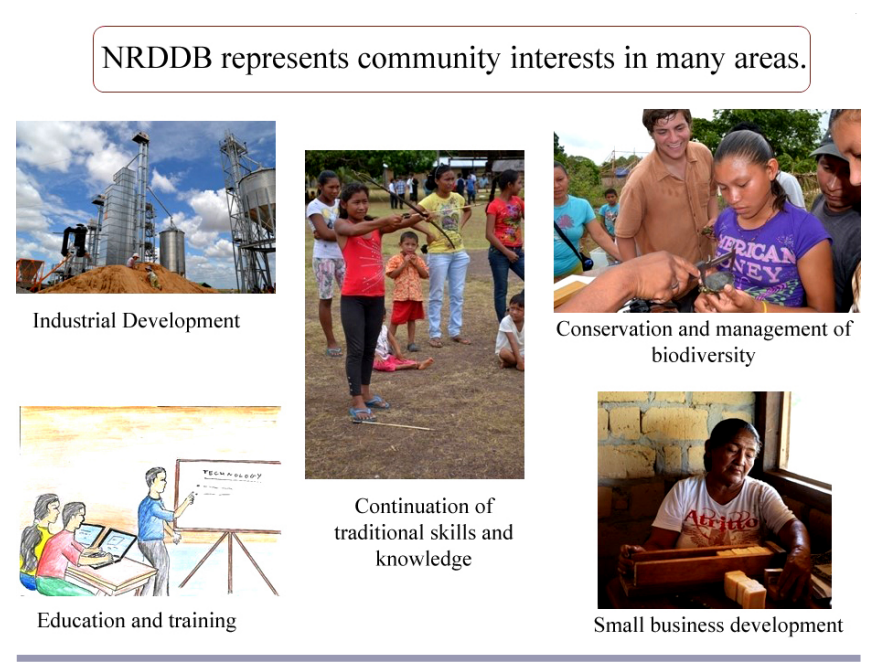

A key role of these partnerships and networks is capacity building. Experience from the best practices show that some effective capacity development has occurred, for example, through the Inter-American Institute for Cooperation on Agriculture and FAO in terms of agriculture (including aquaculture) and for tourism management (e.g., catering, guiding) by the Hospitality Association of Guyana coordinated through the NRDDB. Still, the majority of this support is temporary. Networks and 
associations have also been used to act as a platform for learning and knowledge exchange. In the resistance best practice, for example, we see young people in Yupukari using Internet communication tools to exchange their local experiences and practices with those abroad. Of course, it is important to point out that partnerships involve trade-offs that often mean that communities have to take on obligations that are not always entirely beneficial to them. So, for example, partnerships that provide the resources to maintain a community radio station and programs on indigenous culture may also require the broadcasting of programs in English, which promote the expert-led and centralizing agenda of nonlocal institutions.

\section{DISCUSSION}

Our research shows that the relatively loose structure of system viability encourages communities to go beyond the "here and now" problems, which understandably can be the first response when asked about their challenges, and engage with a wide diversity of challenges they may be facing. This, we believe, goes beyond present-day resilience thinking, which places greater emphasis on understanding how a system persists in the face of change, and its ability to change into more desirable states when required (Folke 2006, Walker et al.2010), compared to what might maintain stability. For example, in a study of the history of an indigenous Māori group in New Zealand, Rotarangi and Stephenson (2014) show that the key resilience concepts of adaptation and transformation were helpful in analyzing the trajectory of change, but fell short of representing the maintenance of a strong cultural identity and connectedness to land. Our research addresses this issue, showing that different strategies to challenges are not mutually exclusive, but that a social-ecological system can simultaneously have both change and stability responses (Berardi et al. 2013b, Mistry et al. 2015a). Crucially, our system viability framework enabled the identification of best practices that actually have synergistic effects and are mutually reinforcing, i.e., they do not necessarily focus on promoting one aspect of a community while undermining other aspects. For example, self-help is practiced in traditional fishing, traditional farming, as part of ecotourism, and in cultural transmission.

Our participatory visual approach also highlights that the boundaries between social and ecological elements of any linked system are blurred, and there are continual interactions and feedbacks in a dynamic manner. In particular, many of the indicators in the system viability assessment have relational/ process characteristics rather than state characteristics. They focus on what people know about the environment, how they access resources, how often they use resources, rather than the quantity of a resource or its health per se. Indigenous worldviews are inherently and implicitly relational and process-oriented (Mistry 2009), where the multifaceted aspects of the human and nonhuman worlds exchange material, energy, and spirits, and the past and future characterize the present (e.g., Berkes 1999, Rose 2005). This points to taking a relational approach to dealing with complexity in social-ecological systems: what these systems are is not just about how they appear or function, but also what they do, how they develop, and how they are linked to other elements of the social-ecological environment (Howitt 2001). The best practice films and photostories have been screened at a number of local, national, and international governance settings, and have helped toward legitimizing the indigenous worldview, both for indigenous people in feeling pride about themselves and for the nonindigenous in acknowledging the need for alternative visions for social-ecological system governance (Mistry et al. 2015c).

Despite the many positives of our approach, we are aware that the system viability framework is another top-down attempt to promote a big picture view of the situation, just as the technocentric approach of using video and audio capturing and editing technologies could be described as an imposition on traditional forms of communication (see Mistry et al. 2009, Mistry and Berardi 2012 for reflections on these issues). In addition, some systems approaches have been criticized for their inability to engage with issues of agency and power (e.g., Brown and Westaway 2011, Fisher et al. 2013). We addressed these concerns by ensuring that men, women, and young people of all ages were part of our participatory processes, and that when analyzing the visual materials we looked to see which individuals/ groups said what. For example, youths tended to focus on adaptation strategies with a strong emphasis on new technologies, elder women gave attention to traditional practices and culture, whereas many men emphasized issues of security and rules (Mistry et al. 2015a). Our objective within the participatory processes was to engage the "researched" in order to transform them into "researchers" of their own situation, while being explicit about everyone's positionality within the investigation, from the individual community groups to our own (Mistry et al. 2015b). This takes time; although the use of a participatory visual approach allowed the collection of a highly qualitative and rich dataset, engagement with the images, and associated discussions with participants was not an easy task, and arriving at a clear interpretation of meaning attributed to the recorded imagery took several iterations of community consultations.

Interventions at community level could be weighed up against survival strategies to identify trade-offs and/or synergies in maintaining the system viability of a community. Our research shows that like many other indigenous communities, there is a great tension between resistance (how to keep traditional knowledge and practices within a healthy natural environment) and adaptability (how to incorporate nonindigenous technologies and life-styles in day-to-day life). Young people in particular vocalized these concerns, keenly feeling the lure of new ways of life and wanting to be seen as modern, but wanting to maintain skills and knowledge as part of their indigenous identity (Mistry et al. 2015a). At the same time, the current dominance of marketbased interventions for managing natural resources could have negative repercussions on community coherence and equity in societies with a strong communal ethic (Plagányia et al. 2013). In our case, we found that collective values and spirit was a crosscutting theme in all the best practices, and that women were a core part of the self-help best practice being undertaken in the North Rupununi, e.g., organizing food sharing. This suggests that not only could market-based approaches with financial incentives potentially disrupt overall community cohesion and associated collaboration, norms of reciprocity, solidarity, and collective action (Godoy et al. 2005), but negative effects on women could be at the forefront of this impact (Westermann et al. 2005).

The six best practices identified by the communities and documented using films and photostories are examples of shared 
Fig. 9. The six best practices from the North Rupununi, Guyana and their relevance at the national and international levels.

\section{Need to incorporate sustainable resource management practices for promoting ecosystem integrity and food security}

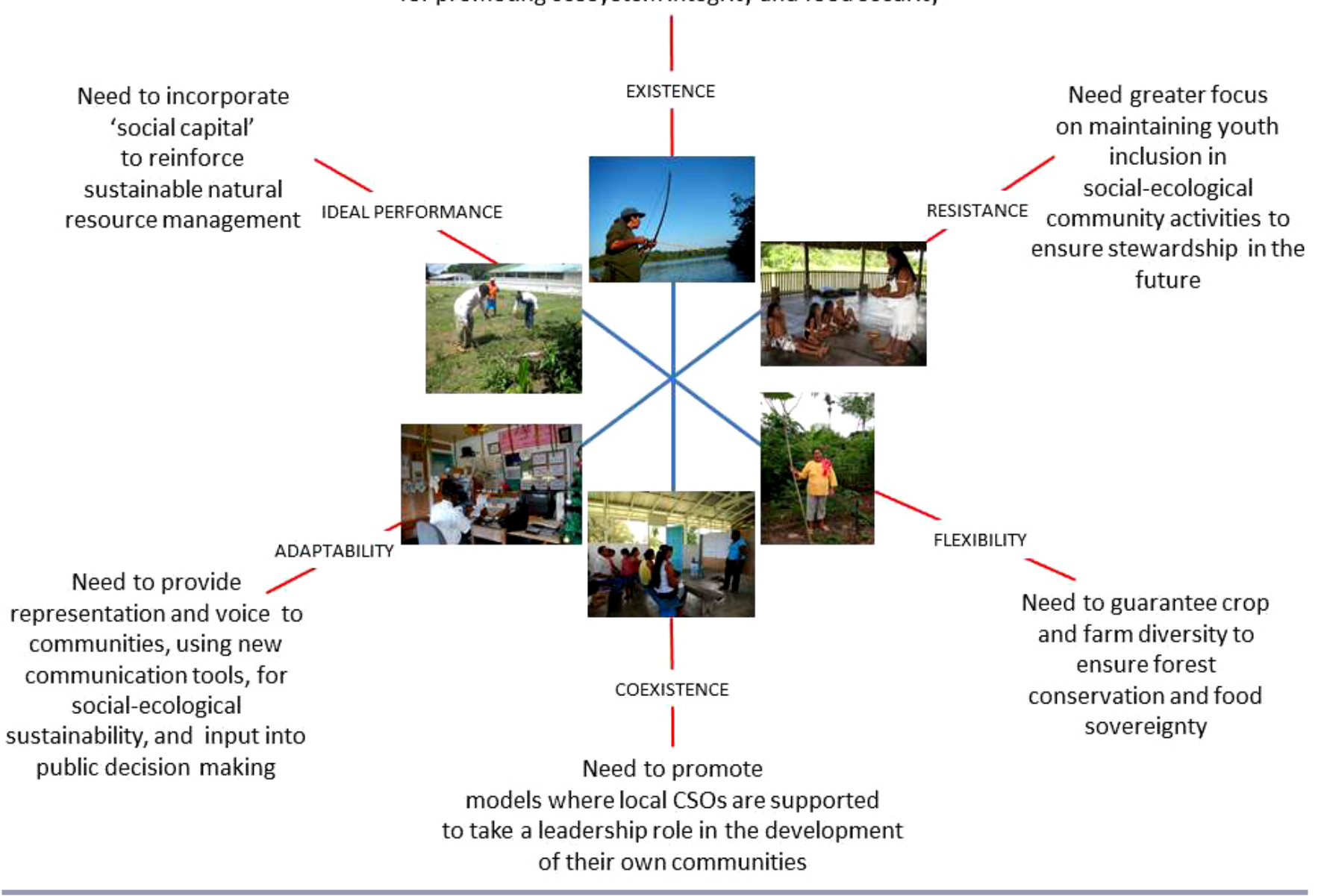

narratives that embrace a diversity of survival strategies. They are examples of community owned solutions that national and international policies should focus on to implement sustainable development programs (Fig. 9). Traditional fisheries (existence), for example, make a significant contribution to many indigenous communities in terms of diet (and associated culture and belief systems), maintaining food chains and biodiversity, and providing income through ecotourism ventures, as outlined in the coexistence best practice (Berkes 2003, Allan et al. 2005, IngwallKing 2014). Yet, in the North Rupununi, economically important species such as the Lukanani (Cichla ocellaris) and Arapaima (Arapaima gigas), as well as traditional food sources, including the Paku (Colossoma bidens), are being targeted for markets in Brazil via some commercial fishing being undertaken by local communities (e.g., Ingwall King 2014), as well as illegal fishing by outsiders. In light of the threat of overharvesting, particularly through the use of seine nets, and to promote sustainable fishing practices, a fisheries management plan was drawn up by the communities of the North Rupununi and the NRDDB (Jafferally and Haynes 2011). However, to date, except for the incorporation of some components of this plan in the government inland fisheries strategic plan, there has been little representation and promotion of local fishing practices at the national level.
Traditional rotational farming (flexibility) not only provides the foundation of people's nutrition, but also their economies, ecologies, and culture. We see this clearly in the best practice where, as food is grown, harvested, processed, consumed, and sold, people are making associations with the protection and conservation of the environment, maintenance of local culture, and income and livelihoods benefits. Promoting traditional cassava growing and processing, can help maintain existence with the everyday consumption of cassava and its products, and resistance as cassava is linked to various cultural activities and events. It has been shown that traditional farming practices actually enhance both soil (biochar) and above ground (higher biomass) carbon storage in the long term and over greater spatial scales (Erni 2009). There is also growing evidence that shifting cultivation has high productivity for the amount of energy and other inputs that they utilize because of the multiple outputs, not all of which are recognized or valued in external markets (Trosper et al. 2012). Thus, traditional farming methods and associated knowledge can make significant contributions to sustainable forest conservation and management, particularly in relation to climate change mitigation policies such as REDD+. 
It is clear, however, that community owned solutions do not exist in isolation, and that higher level social-ecological systems can either have a supporting or undermining effect. The cross-cutting best practice themes of indigenous knowledge, leadership, and partnerships were also themes that emerged from a cross-scalar analysis of environmental governance in the Guiana Shield (Berardi et al. 2015). Although good leadership and solidarity were identified as essential at the local level (Gruber 2010, 2011, Gutiérrez et al. 2011, Kenward et al. 2011), especially during times of variable pressures and resource scarcity, the extent to which leaders had autonomy and support in decision making was repeatedly questioned. This is in light of Guyana's poor record in governance, with the control of corruption, regulatory quality in the formulation and implementation of policies, and regulations permitting and promoting private sector development, such as in the resource extraction industries, particularly problematic (World Bank 2014). Poor governance also influences the effectiveness of partnerships in collaborative initiatives such as capacity-building activities that take significant effort and time, and require sustained and stable cooperation and funding at regional and national scales. Critically, indigenous knowledge needs to be recognized as a valid form of information for decision making at higher scales of governance, while being protected from exploitation and misapplication through appropriate measures to protect sensitive information (Taylor 2006). Legitimizing indigenous knowledge could help to mitigate against the current rapid transition toward a Western lifestyle of many indigenous communities, to the potential detriment of conservation initiatives. Once networked into global socioeconomic systems, these communities find it difficult to go back to an isolated, preglobalization lifestyle, and so the challenge is to find ways in which communities can constructively adapt to globalization without totally losing their indigenous cultures and lifestyles, and degrading their natural environment.

A prerequisite to this end is land tenure and rights. Indigenous communities are striving to secure access to territory to maintain traditional land-use practices and the ability to exploit future income-generating activities (Berardi et al. 2015). However, in the case of Guyana, it is still a nonsignatory of the Convention on Indigenous and Tribal Peoples (Convention ILO $n^{\circ} 169$ ), and although the government is committed to increasing indigenous land rights through the Amerindian Act of 2006, limited progress has been achieved to date in granting customary territories traditionally used to maintain livelihoods.

\section{CONCLUSIONS}

Our system viability and participatory visual approach suggests that community-based natural resource management requires a suite of strategies that the local communities who are part of the social-ecological system have themselves identified and assessed. In our case this included traditional ecological knowledge linked to local cultural values, the transmission of this knowledge throughout the community but especially to young people, strong local CSOs and community leaders, a collective spirit with a degree of personal sacrifice, support when needed from external bodies/organizations, and adoption/use of new communication technologies. However, system viability also allows the surfacing of tensions between survival strategies championed by different members of the community. This, we argue, is a healthy manifestation of a thriving and resilient community, as long as competing strategies are able to be maintained. What distinguishes our approach from many interventions is that we sought to identify and promote the solutions that community members themselves were practising, without ongoing assistance from external stakeholders. An exploration of their own socialecological system can help communities to plan governance and management of land and resource systems, while reinforcing sustainable practices by discussing and showcasing them within communities, and by engendering a sense of pride in local solutions. In light of growing evidence for legally recognized indigenous territories maintaining biodiverse forest and land cover (e.g., Carranza et al. 2014, Stevens et al. 2014), providing more examples and details about community owned solutions and best practices could contribute toward greater autonomy in governance for indigenous communities. Further research needs to monitor community owned solutions over time, corroborated with empirical environmental information on land cover/quality change, as well as find ways to increase the presence of community owned solutions within the conservation, development, and political agenda.

Responses to this article can be read online at: http://www.ecologyandsociety.org/issues/responses. $\mathrm{php} / 8496$

\begin{abstract}
Acknowledgments:
We would like to thank all the communities of the North Rupununi, Guyana for their active and enthusiastic participation in this research. We also thank all project partners for their contributions to the research and the reviewers for their pertinent comments that greatly helped to improve the paper. This research was funded by the Environment Programme, Management of Natural Resources, $D G$ Research and Innovation, European Commission 7th Framework.
\end{abstract}

\section{LITERATURE CITED}

Agrawal, A. 2003. Sustainable governance of common-pool resources: context, methods, and politics. Annual Review of Anthropology 32:243-262. http://dx.doi.org/10.1146/annurev. anthro.32.061002.093112

Allan, J. D., R. Abell, Z. Hogan, C. Revenga, B. W. Taylor, R. L. Welcomme, and K. Winemiller. 2005. Overfishing of inland waters. BioScience 55(12):1041-1051. http://dx.doi.org/10.1641/0006-3568 (2005)055[1041:ooiw]2.0.co;2

Armitage, D. R., R. Plummer, F. Berkes, R. I. Arthur, A. T. Charles, I. J. Davidson-Hunt, A. P. Diduck, N. C. Doubleday, D. S. Johnson, M. Marschke, P. McConney, E. W. Pinkerton, and E. K. Wollenberg. 2009. Adaptive co-management for socialecological complexity. Frontiers in Ecology and the Environment 7(2):95-102. http://dx.doi.org/10.1890/070089

Belton, V., and T. J. Stewart. 2002. Multiple criteria decision analysis. An integrated approach. Kluwer Academic Publishers, Massachusetts, USA. http://dx.doi.org/10.1007/978-1-4615-1495-4

Béné, C., L. Evans, D. Mills, S. Ovie, A. Raji, A. Tafida, A. Kodio, F. Sinaba, P. Morand, J. Lemoalle, and N. Andrew. 2011. Testing resilience thinking in a poverty context: experience from the Niger 
River basin. Global Environmental Change 21:1173-1184. http:// dx.doi.org/10.1016/j.gloenvcha.2011.07.002

Berardi, A., E. Bignante, J. Mistry, M. Simpson, C. Tschirhart, C. Verwer, and G. de Ville. 2014. How to find and share community owned solutions. A handbook. Project COBRA, London, UK. [online] URL: http://projectcobra.org/how-tofind-and-share-community-owned-solutions

Berardi, A., J. Mistry, C. Tschirhart, E. Bignante, O. Davis, L. Haynes, R. Benjamin, G. Albert, R. Xavier, D. Jafferally, and G. de Ville. 2015. Applying the system viability framework for crossscalar governance of nested social-ecological systems in the Guiana Shield, South America. Ecology and Society 20(3):42. http://dx.doi.org/10.5751/es-07865-200342

Berardi, A., J. Mistry, C. Tschirhart, C. Verwer, R. Glastra, G. de Ville, O. Davis, C. de Souza, L. Haynes, R. Benjamin, R. Xavier, G. Albert, D. Jafferally, E. Bignante, and J. Abraham. $2013 a$. Second report on the cross-scalar interactions and compatibilities governing sustainable development and ecosystem service management of the Guiana Shield: drivers of social and environmental degradation, and policy responses. The Open University, Milton Keynes, UK. [online] URL: http:// projectcobra.org/second-report-on-cross-scalar-actions-andcompatibilities/

Berardi, A., C. Tschirhart, J. Mistry, E. Bignante, L. Haynes, G. Albert, R. Benjamin, R. Xavier, and D. Jafferally. 2013b. From resilience to viability: a case study of indigenous communities of the North Rupununi, Guyana. EchoGéo 24. [online] URL: http:// echogeo.revues.org/13411

Berkes F. 1999. Sacred ecology: traditional ecological knowledge and resource management. Taylor \& Francis, Philadelphia, Pennsylvania, USA.

Berkes, F. 2003. Alternatives to conventional management: lessons from small-scale fisheries. Environments 31(1):5-20.

Berkes, F. 2007. Adaptive co-management and complexity: exploring the many faces of co-management. Pages 19-37 in D. Armitage, F. Berkes and N. Doubleday, editors. Adaptive comanagement: collaboration, learning, and multi-level governance. University of British Columbia Press, Vancouver, British Columbia, Canada.

Berkes, F. 2012. Sacred ecology: traditional ecological knowledge and resource management. Taylor and Francis, Philadelphia, Pennsylvania, USA.

Bignante, E. 2010. The use of photo elicitation in field research: exploring Maasai representations and use of natural resources. EchoGéo 11. [online] URL: http://echogeo.revues.org/index11622. html http://dx.doi.org/10.4000/echogeo.11622

Blom, B., T. Sunderland, and D. Murdiyarso. 2010. Getting REDD to work locally: lessons learned from integrated conservation and development projects. Environmental Science \& Policy 13:164-172. http://dx.doi.org/10.1016/j.envsci.2010.01.002

Bossel, H. 1999. Indicators for sustainable development - theory, method, applications. A report to the Balaton Group. International Institute for Sustainable Development, Winnipeg, Manitoba, Canada.
Bossel, H. 2001. Assessing viability and sustainability: a systemsbased approach for deriving comprehensive indicator sets. Conservation Ecology 5(2):12. [online] URL: http://www. consecol.org/vol5/iss2/art12/

Bossel, H. 2007. Systems and models: complexity, dynamics, evolution, sustainability. Books on Demand, Norderstedt, Germany.

Brown, K., and E. Westaway. 2011. Agency, capacity, and resilience to environmental change: lessons from human development, well-being, and disasters. Annual Review of Environment and Resources 36:321-342. http://dx.doi.org/10.1146/ annurev-environ-052610-092905

Carranza, T., A. Balmford, V. Kapos, and A. Manica. 2014. Protected area effectiveness in reducing conversion in a rapidly vanishing ecosystem: the Brazilian Cerrado. Conservation Letters 7(3):216-223. http://dx.doi.org/10.1111/conl.12049

Cox, M., G. Arnold, and S. Villamayor Tomás. 2010. A review of design principles for community-based natural resource management. Ecology and Society 15(4):38. [online] URL: $\underline{\text { http:// }}$ www.ecologyandsociety.org/vol15/iss4/art38/

Davis, C., L. Williams, S. Lupberger, and F. Daviet. 2013. Assessing forest governance. The governance of forests initiative indicator framework. World Resources Institute, Washington D. C., USA.

Dryzek, J. S. 2005. The politics of the Earth: environmental discourses. Second Edition. Oxford University Press, Oxford, UK.

Erni, C. 2009. Shifting the blame? Southeast Asia's indigenous peoples and shifting cultivation in the age of climate change. Paper presented at the seminar on Adivasi/ST Communities in India. Development and Change, Delhi, August 27-29, 2009, IWGIA. [online] URL: http://unfccc.int/resource/docs/2012/smsn/ngo/243. pdf

Fernandez-Gimenez, M. E., H. L. Ballard, and V. E. Sturtevant. 2008. Adaptive management and social learning in collaborative and community-based monitoring: a study of five communitybased forestry organizations in the western USA. Ecology and Society 13(2):4. [online] URL: http://www.ecologyandsociety. org/vol13/iss2/art4/

Fisher, J. A., G. Patenaude, P. Meir, A. J. Nightingale, M. D. A. Rounsevell, M. Williams, and I. H. Woodhouse. 2013. Strengthening conceptual foundations: analysing frameworks for ecosystem services and poverty alleviation research. Global Environmental Change 23(5):1098-1111. http://dx.doi.org/10.1016/ j.gloenvcha.2013.04.002

Folke, C. 2006. Resilience: the emergence of a perspective for social-ecological systems analyses. Global Environmental Change 16:253-267. http://dx.doi.org/10.1016/j.gloenvcha.2006.04.002

Folke, C., T. Hahn, P. Olsson, and J. Norberg. 2005. Adaptive governance of social-ecological systems. Annual Review of Environment and Resources 30:441-473. http://dx.doi.org/10.1146/ annurev.energy.30.050504.144511

Galappaththi, E. K., and F. Berkes. 2015. Drama of the commons in small-scale shrimp aquaculture in northwestern Sri Lanka. 
International Journal of the Commons 9:347-368. http://dx.doi. org/10.18352/ijc. 500

Gaveau, D. L. A., J. Epting, O. Lyne, M. Linkie, I. Kumara, M. Kanninen, and N. Leader-Williams. 2009. Evaluating whether protected areas reduce tropical deforestation in Sumatra. Journal of Biogeography 36:2165-2175. http://dx.doi.org/10.1111/ j.1365-2699.2009.02147.x

Godoy, R., V. Reyes-García, E. Byron, W. R. Leonard, and V. Vadez. 2005. The effect of market economies on the well-being of indigenous peoples and on their use of renewable natural resources. Annual Review of Anthropology 34:121-138. http://dx. doi.org/10.1146/annurev.anthro.34.081804.120412

Gruber, J. S. 2010. Key principles of community-based natural resource management: a synthesis and interpretation of identified effective approaches for managing the commons. Environmental Management 45:52-66. http://dx.doi.org/10.1007/s00267-008-9235$\underline{\mathrm{y}}$

Gruber, J. S. 2011. Perspectives of effective and sustainable community-based natural resource management: an application of Q methodology to forest projects. Conservation and Society 9 (2):159-171. http://dx.doi.org/10.4103/0972-4923.83725

Gutiérrez, N. L., R. Hilborn, and O. Defeo. 2011. Leadership, social capital and incentives promote successful fisheries. Nature 470:386-389. http://dx.doi.org/10.1038/nature09689

Hall, G., and H. A. Patrinos, editors. 2005. Indigenous peoples, poverty and human development in Latin America. Palgrave Macmillan, Basingstoke, UK. http://dx.doi.org/10.1057/9780230377226

Hammond, D. S., editor. 2005. Tropical forests of the Guiana Shield: ancient forests in a modern world. CABI, Cambridge, Massachusetts, USA. http://dx.doi.org/10.1079/9780851995366.0000

Howitt, R. 2001. Rethinking resource management: justice, sustainability and indigenous peoples. Psychology Press, Routledge, London, UK. http://dx.doi.org/10.4324/9780203221020

Ingwall-King, L. 2014. The implications of spatial and temporal scale on the supply, distribution and value of ecosystem services in Guyana. Dissertation, Royal Holloway University of London, UK.

Jafferally, D., and L. Haynes. 2011. Co-management plan for fisheries in the North Rupununi Wetlands. Iwokrama International Centre, Georgetown, Guyana.

Kamuya, D. M., S. J. Theobald, P. K. Munywoki, D. Koech, W. P. Geissler, and S. C. Molyneux. 2013. Evolving friendships and shifting ethical dilemmas: fieldworkers' experiences in a short term community based study in Kenya. Developing World Bioethics 13(1):1-9. http://dx.doi.org/10.1111/dewb.12009

Kenward, R. E., M. J. Whittingham, S. Arampatzis, B. D. Manos, T. Hahne, A. Terry, R. Simoncini, J. Alcorn, O. Bastian, M. Donlan, K. Elowe, F. Franzén, Z. Karacsonyi, M. Larsson, D. Manou, I. Navodaru, O. Papadopoulou, J. Papathanasiou, A. von Raggamby, R. J. A. Sharp, T. Söderqvist, A. Soutukorva, L. Vavrova, N. J. Aebischer, N. Leader-Williams, and C. Rutzt. 2011. Identifying governance strategies that effectively support ecosystem services, resource sustainability, and biodiversity. Proceedings of the National Academy of Sciences of the United
States of America 108(13):5308-5312. http://dx.doi.org/10.1073/ pnas. 1007933108

Khadka, C., and H. Vacik. 2012. Use of multi-criteria analysis (MCA) for supporting community forest management. iForest 5:60-71 http://dx.doi.org/10.3832/ifor0608-009

Lunch, N., and C. Lunch. 2006. Insights into participatory video. InsightShare, Oxford, UK.

McGinnis, M. D., and E. Ostrom. 2014. Social-ecological system framework: initial changes and continuing challenges. Ecology and Society 19(2):30. [online] URL: http://www.ecologyandsociety. org/vol19/iss2/art30/ http://dx.doi.org/10.5751/es-06387-190230

Mendoza, G. A., and R. Prabhu. 2005. Combining participatory modeling and multi-criteria analysis for community-based forest management. Forest Ecology and Management 207(1-2):145-156. http://dx.doi.org/10.1016/j.foreco.2004.10.024

Millennium Ecosystem Assessment. 2005. Ecosystems and human well-being: health synthesis. Millennium Ecosystem Assessment and World Health Organization, Geneva, Switzerland. [online] URL: http://www.who.int/entity/globalchange/ecosystems/ecosys. pdf

Milne, E. J., C. Mitchell, and N. De Lange 2012. Handbook of participatory video. AltaMira Press, Lanham, Maryland, USA.

Mistry J. 2009. Indigenous knowledges. Pages 371-376 in R. Kitchin and N. Thrift, editors. International encyclopedia of human geography, Volume 5. Elsevier, Oxford, UK. http://dx.doi. org/10.1016/b978-008044910-4.00101-2

Mistry, J., and A. Berardi. 2012. The challenges and opportunities of participatory video in geographical research: exploring collaboration with indigenous communities of the North Rupununi, Guyana. Area 44:110-116. http://dx.doi.org/10.1111/ j.1475-4762.2011.01064.x

Mistry, J., A. Berardi, E. Bignante, and C. Tschirhart. $2015 b$. Between a rock and a hard place: ethical dilemmas of local community facilitators doing participatory projects. Geoforum 61:27-35. http://dx.doi.org/10.1016/j.geoforum.2015.02.010

Mistry, J., A. Berardi, and M. Simpson. 2009. Critical reflections on practice: the changing roles of three physical geographers carrying out research in a developing country. Area 41(1):82-93. http://dx.doi.org/10.1111/j.1475-4762.2008.00841.x

Mistry, J., A. Berardi, M. Simpson, O. Davis, and L. Haynes. 2010. Using a systems viability approach to evaluate integrated conservation and development projects: assessing the impact of the North Rupununi Adaptive Management Process, Guyana. Geographical Journal 176(3):241-252. http://dx.doi.org/10.1111/ j.1475-4959.2010.00357.x

Mistry, J., A. Berardi, C. Tschirhart, E. Bignante, L. Haynes, R. Benjamin, G. Albert, R. Xavier, D. Jafferally, and G. de Ville. 2015a. Indigenous identity and environmental governance in Guyana, South America. Cultural Geographies 22(4):689-712. http://dx.doi.org/10.1177/1474474014560998

Mistry, J., A. Berardi, C. Verwer, and G. de Ville. 2015c. Up-scaling support for community owned solutions. A Project COBRA report for policy makers. Project COBRA, London, UK. [online] URL: http://projectcobra.org/up-scaling-support-for-community-owned$\underline{\text { solutions }}$ 
Mistry, J., M. Simpson, A. Berardi, and Y. Sandy. 2004. Exploring the links between natural resource use and biophysical status in the waterways of the North Rupununi, Guyana. Journal of Environmental Management 72:117-131. http://dx.doi.org/10.1016/ j.jenvman.2004.03.010

Mistry, J., C. Tschirhart, C. Verwer, R. Glastra, O. Davis, D. Jafferally, L. Haynes, R. Benjamin, G. Albert, R. Xavier, I. Bovolo, and A. Berardi. 2014. Our common future? Cross-scalar scenario analysis for social-ecological sustainability of the Guiana Shield, South America. Environmental Science \& Policy 44:126-148. http://dx.doi.org/10.1016/j.envsci.2014.05.007

Open University 2002. Systems thinking and practice: diagramming. The Open University, Milton Keynes, UK.

Ostrom, E. 1990. Governing the commons: the evolution of institutions for collective action. Cambridge University Press, Cambridge, UK. http://dx.doi.org/10.1017/CBO9780511807763

Ostrom, E. 1999. Coping with tragedies of the commons. Annual Review of Political Science 2:493-535. http://dx.doi.org/10.1146/ annurev.polisci.2.1.493

Ostrom, E. 2009. A general framework for analyzing sustainability of social-ecological systems. Science 325 (5939):419-422. http://dx.doi.org/10.1126/science.1172133

Ostrom, E., and M. Cox. 2010. Moving beyond panaceas: a multitiered diagnostic approach for social-ecological analysis. Environmental Conservation 37(4):451-463. http://dx.doi.org/10.1017/ $\underline{\mathrm{s} 0376892910000834}$

Ostrom, E., M. A. Janssen, and J. M. Anderies. 2007. Going beyond panaceas. Proceedings of the National Academy of Sciences of the United States of America 104(39):15176-15178. http://dx.doi.org/10.1073/pnas.0701886104

Pain, R., M. Kesby, and K. Askins. 2012. The politics of social justice in neoliberal times: a reply to Slater. Area 44(1):120-123. http://dx.doi.org/10.1111/j.1475-4762.2011.01073.x

Plagányia, É. E., I. van Putten, T. Hutton, R. A. Deng, D. Dennis, S. Pascoe, T. Skewes, and R. A. Campbell. 2013. Integrating indigenous livelihood and lifestyle objectives in managing a natural resource. Proceedings of the National Academy of Sciences of the United States of America 110(9):3639-3644. http://dx.doi. org/10.1073/pnas. 1217822110

Plummer, R. 2009. The adaptive co-management process: an initial synthesis of representative models and influential variables. Ecology and Society 14(2):24. [online] URL: http://www. ecologyandsociety.org/vol14/iss2/art24/

Plummer, R., B. Crona, D. R. Armitage, P. Olsson, M. Tengö, and O. Yudina. 2012. Adaptive comanagement: a systematic review and analysis. Ecology and Society 17(3):11. http://dx.doi. org/10.5751/es-04952-170311

Porter-Bolland, L., E. A. Ellis, M. R. Guariguata, I. Ruiz-Mallén, S. Negrete-Yankelevich, and V. Reyes-García. 2012. Community managed forests and forest protected areas: an assessment of their conservation effectiveness across the tropics. Forest Ecology and Management 268:6-17. http://dx.doi.org/10.1016/j.foreco.2011.05.034

Poteete, A. R., and E. Ostrom. 2004. Heterogeneity, group size and collective action: the role of institutions in forest management. Development and Change 35(3):435-461. http://dx. doi.org/10.1111/j.1467-7660.2004.00360.X

Recchia, L., P. Boncinelli, E. Cini, M. Vieri, F. G. Pegna, and D. Sarri. 2011. Multicriteria analysis and LCA techniques. Springer, Dordrecht, The Netherlands. http://dx.doi.org/10.1007/978-0-85729-704-4

Reed, M. S., A. J. Dougill, and T. R. Baker. 2008. Participatory indicator development: what can ecologists and local communities learn from each other? Ecological Applications 18:1253-1269. http://dx.doi.org/10.1890/07-0519.1

Reed, M., E. D. G. Fraser, S. Morse, and A. J. Dougill. 2005. Integrating methods for developing sustainability indicators to facilitate learning and action. Ecology and Society 10(1):r3. [online] URL: http://www.ecologyandsociety.org/vol10/iss1/ resp31

Rockström, J., W. Steffen, K. Noone, Å. Persson, F. S. Chapin III, E. F. Lambin, T. M. Lenton, M. Scheffer, C. Folke, H. J. Schellnhuber, et al. 2009. A safe operating space for humanity. Nature 461(7263):472-475. http://dx.doi.org/10.1038/461472a

Rose, D. 2005. An indigenous philosophical ecology: situating the human. Australian Journal of Anthropology 16(3):294-305. http:// dx.doi.org/10.1111/j.1835-9310.2005.tb00312.x

Rotarangi, S. J., and J. Stephenson. 2014. Resilience pivots: stability and identity in a social-ecological-cultural system. Ecology and Society 19(1):28. http://dx.doi.org/10.5751/ es-06262-190128

Stevens, C., R. Winterbottom, K. Reytar, and J. Springer. 2014. Securing rights, combating climate change. How strengthening community forest rights mitigates climate change. World Resources Institute, Washington, D.C., USA. [online] URL: http://www.wri. org/securingrights

Stringer, L. C., A. J. Dougill, E. Fraser, K. Hubacek, C. Prell, and M. S. Reed. 2006. Unpacking "participation" in the adaptive management of social-ecological systems: a critical review. Ecology and Society 11(2):39. [online] URL: http://www. ecologyandsociety.org/vol11/iss2/art39/

Taylor J. 2006. Indigenous peoples and indicators of well-being: an Australian perspective on UNPFII Global Frameworks. Working Paper No. 33/2006. Centre for Aboriginal Economic Policy Research, Australian National University, Canberra, Australia. [online] URL: http://caepr.anu.edu.au/Publications/WP/2006WP33. php

Trosper, R. L., J. A. Parrotta, M. Agnoletti, V. Bocharnikov, S. A. Feary, M. Gabay, C. Gamborg, J. G. Latorre, E. Johann, A. Laletin, L. H. Fui, A. Oteng-Yeboah, M. Pinedo-Vasquez, P. S. Ramakrishnan, and Y. Yeo-Chang. 2012. The unique character of traditional forest-related knowledge: threats and challenges ahead. Pages 563-588 in J. A. Parrotta and R. L. Trosper, editors. Traditional forest-related knowledge: sustaining communities, ecosystems and biocultural diversity. Springer, Dordrecht, The Netherlands. http://dx.doi.org/10.1007/978-94-007-2144-9 15

Tschirhart, C., J. Mistry, A. Berardi, E. Bignante, M. Simpson, L. Haynes, R. Benjamin, G. Albert, R. Xavier, B. Robertson, O. Davis, C. Verwer, G. De Ville, and D. Jafferally. 2016. Learning from one another: evaluating the impact of horizontal knowledge 
exchange for environmental management and governance. Ecology and Society 21(2):41. http://dx.doi.org/10.5751/ ES-08495-210241

Tschirhart, C., J. Mistry, M. Simpson, A. Berardi, C. Verwer, G. de Ville, and E. Bignante. 2014. Report on best practice sharing, implementation and evaluation. Royal Holloway and Bedford New College, University of London, UK. [online] URL: http:// projectcobra.org/work-package-5-report

United Nations Development Programme (UNDP). 2012. The power of local action: learning from communities on the frontlines of sustainable development. UNDP, New York, New York, USA.

Walker, B., L. Pearson, M. Harris, K. G. Maler, C. Z. Li, R. Biggs, and T. Baynes. 2010. Incorporating resilience in the assessment of inclusive wealth: an example from South East Australia. Environmental and Resource Economics 45(2):183-202. http://dx. doi.org/10.1007/s10640-009-9311-7

Westermann, O., J. Ashby, and J. Pretty. 2005. Gender and social capital: the importance of gender differences for the maturity and effectiveness of natural resource management groups. World Development 33(11):1783-1799. http://dx.doi.org/10.1016/j. worlddev.2005.04.018

Wetlands Partnership. 2006. State of the North Rupununi report. Wetlands Partnership, Georgetown, Guyana.

Wetlands Partnership. 2008. The North Rupununi adaptive management process (NRAMP). Wetlands Partnership, Georgetown, Guyana.

Wheeler, J. 2009. 'The life that we don't want': using participatory video in researching violence. IDS Bulletin 40(3):10-18. http://dx. doi.org/10.1111/j.1759-5436.2009.00033.x

White, S. A., editor. 2003. Participatory video: images that transform and empower. Sage, London, UK.

World Bank. 2014. The worldwide governance indicators. World Bank, Washington, D.C., USA. [online] URL: http://info. worldbank.org/governance/wgi/index.aspx\#home 